\title{
DE LA INNECESARIA NECESIDAD DE LA TRADUCCIÓN
}

\author{
OF THE UNNECESSARY NEED FOR TRANSLATION
}

\author{
José Francisco Ruiz Casanova \\ Universidad Pompeu Fabra
}

\section{ABSTRACT}

The article deals with the place of translation (and literary translation) in the world after 9/11 and the pandemics, what the role of educational institutions and Translation Studies is and has been, and which is the place of the two main activities of the translator: reading and writing.

Key words: Translation, Literature, Reading, Writing.

\section{RESUMEN}

El artículo trata del lugar de la traducción (y de la traducción literaria) en el mundo posterior al 11-S y las pandemias, cuál es y ha sido el papel de las instituciones educativas y de los Estudios de Traducción y dónde se sitúan las dos actividades connaturales del traductor: la lectura y la escritura.

Palabras clave: Traducción, Literatura, Lectura, Escritura. 
Fecha de recepción: 21 de septiembre de 2021.

Fecha de aceptación: 29 de septiembre de 2021.

Cómo citar: Ruiz Casanova, José Francisco (2021): «De la innecesaria necesidad de la traducción», en Actio Nova: Revista de Teoría de la Literatura y Literatura Comparada, monográfico 5: $213-222$.

DOI: https://doi.org/10.15366/actionova2021.m5.010 
Quisiera aprovechar estas páginas para insistir en una cuestión que apenas esbocé, de forma epilogal, en mi ensayo Traducir la traducción (2020): la presencia y la desaparición de una idea de centralidad (la centralidad de la traducción) en las culturas actuales. Se trata de un fenómeno que ha corrido parejo al auge, desarrollo e hipertrofia de los Estudios de Traducción, parte voluntaria o involuntaria de la percepción cada vez más mecanicista y menos humanística de la traducción (también literaria) que, huelga decirlo, fue uno de los principales pilares de la transmisión de la cultura clásica y de la fundación de las culturas modernas.

Me preguntaba entonces por el espacio que ocupará la traducción en un mundo donde la lectura es, cada vez menos, elemento crucial en la formación de las identidades ${ }^{1}$. Y habría que preguntarse, en igual medida y para ser justos, qué lugar ocupará la traducción en un mundo donde los Estudios de Traducción han pretendido copar, formalizar, regular e institucionalizar tal cantidad de contenidos e ideas que, como consecuencia, de tal auge supuestamente científico no ha podido verificarse, todavía, mejora alguna en la calidad de las traducciones que se realizan. Lo han advertido muchos, entre ellos Yves Bonnefoy, con poco eco al parecer. Para el crítico y poeta francés, la traducción «trasciende las reflexiones que los especialistas puedan hacer sobre aspectos específicos de la tarea» (Bonnefoy, 2002: 13).

Tres años antes de su muerte, David Foster Wallace impartió una conferencia de graduación en la Universidad de Kenyon, texto que fue impreso en 2009, tras la trágica desaparición del autor, y traducido al español en 2014. La conferencia tiene por título This is water (Esto es agua), y debe semejante epígrafe a la anécdota inicial con la que Foster Wallace comenzó su alocución ante los graduados que le escuchaban:

Había una vez dos peces jóvenes que iban nadando y se encontraron por casualidad con un pez mayor que nadaba en dirección contraria; el pez mayor los saludó con la cabeza y les dijo: «Buenos días, chicos. ¿Cómo está el agua?». Los peces jóvenes siguieron nadando un trecho: por fin, uno de ellos miró al otro y le dijo: «¿Qué demonios es el agua?» (Foster Wallace, 2014: 9-10).

\footnotetext{
${ }^{1}$ Para Edith Grossman, en su optimista (y de ambiguo título en su traducción española) ensayo Por qué la traducción importa, trad. de Elvio E. Gandolfo, Buenos Aires, Katz Editores, 2011, pág. 47: «¿Por qué la traducción importa, y para quién? Creo que importa por los mismos motivos y en el mismo sentido en que la literatura importa: porque es crucial para nuestro sentido de nosotros mismos como seres humanos».
} 
El acceso, aunque deficiente, a una lingua franca y el repliegue de las culturas sobre la tautología de lo propio (nacionalismos lingüísticos) hacen, en determinados contextos, innecesaria la necesidad de la traducción. Esto es, de algún modo, estamos retrotrayéndonos a estadios previos a la descodificación, para los que la impresión del sentido, la aproximación, es suficiente, cuando no la pura invención del mismo. O la ignorancia. Podríamos traer aquí aquella ilustrativa fábula con la que da comienzo el Libro de buen amor, la disputa por la sabiduría entre griegos y romanos, debate que termina celebrándose mediante gestos con las manos y que resulta, como todo en el libro, no sólo episodio cómico sino moraleja y carga de profundidad acerca del sentido, del valor de lo dicho y de su interpretación.

En un contexto en el que la Inteligencia Artificial (IA) ha ocupado el terreno de lo doméstico y viaja con nosotros a diario, la traducción se ha convertido, circunstancialmente, en una operación de mecánica verbal, de algoritmos regidos por la frecuencia y por las capacidades de los gestores informáticos y, en definitiva, una marca de diferencia a la que hemos dejado de conceder importancia.

Y si cabe preguntarse acerca del destino de la traducción en el marco de las culturas sobrevivientes del 11-S (o de las pandemias), no menos ajustado debe ser preguntarse por el lugar de los Estudios de Traducción y de las instituciones que los soportan o les han dado cobijo administrativo. Como los peces de Foster Wallace, pronto los investigadores, de seguir así, se preguntarán, y no desde una perspectiva ontológica, qué demonios es la traducción. En mis cuatro décadas en la universidad española, como alumno y como docente, he asistido al auge y caída de las Filologías, sumidas ahora en centros de enseñanza en los que se imparten las más variadas disciplinas (desde Teoría de la Comunicación hasta el indefinible concepto universitario de Humanidades); y paralelamente a esta caída, el auge y caída inmediatos de las Facultades de Traducción, cuyo esplendor ha durado apenas una década, en términos de vida universitaria. Basta darse un paseo por cualquiera de los portales en que se recogen los títulos de las tesis doctorales leídas en dichas facultades para ver hasta qué punto el discurso mismo ha acabado con el objeto de estudio sin reportarle a éste ni un solo ápice de enriquecimiento.

¿Alguien pretende seguir defendiendo que las Facultades de Traducción y muchos de sus actuales planes de estudio y asignaturas facultan a sus estudiantes como traductores? 
Me temo que los traductores, y sobre todo los traductores literarios (pero no sólo ellos sino todos), siguen emergiendo de una especie de individuo cada vez más extraña y más escasa: el ser lector. Lo demás (la técnica, las capacidades, el atisbo del estilo o de los estilos, el conocimiento de las culturas) va dándose en la medida en que dicho ser lector se transmuta en ser escritor. La cuestión, aquí, es una y axial: dónde aprender a ser lector, o a ser escritor, sin que aceptemos que para leer baste con hacer pública la declaración de intenciones (me gusta leer), o que escribir sea una operación que va más allá de expresar voliciones.

Así las cosas, a la traducción se le ha cargado con la pesada mochila de la teoría, formulada normal y normativamente por quienes nunca han traducido (apenas escrito) ni traducirán, por quienes apenas escribirán otra cosa que papers que se amontonan a modo de escalones en la carrera y el ascenso administrativos ${ }^{2}$. Y esto, a pesar de advertencias, críticas y debates sobre el espacio que los Estudios de Traducción han ocupado (copado) cuando de traducciones hablamos:

Gran parte de la teoría de la traducción que nace en la universidad es de muy poca utilidad para ayudar a alguien a entender lo que es la traducción, o, desde un punto de vista práctico, para ayudar a generar mejores traducciones [...] El resultado es una fisura cada vez mayor entre la traducción como arte o artefacto y ese discurso que tiende a empujarla cada vez más al rincón de la impracticabilidad (Polizzotti, 2020: 56).

Pero de la situación actual no cabe únicamente responsabilizar al sistema educativo, pues éste no es más que el eslabón final de una cadena (y de una filosofía) que comienza en los estamentos legislativos o, en los casos de las democracias parlamentarias, mucho antes, en la propia sociedad que elige o faculta a otros para que elijan el camino de la formación de la propia población que los elige. El abandono de la lectura y de la escritura (una forma de amnesia planificada, según Steiner [2006: 58])., la fascinación (o alucinación) por los soportes informáticos en el aula y en la vida, la misma abreviatura o jibarización del conocimiento, geolocalizado en la primera entrada que nos devuelve el buscador virtual de contenidos, o las propias políticas lingüísticas de los estados y de las naciones son algunas de las realidades que han situado la traducción en una posición ancilar, asistencial, en una vuelta inconsciente (y orgullosa a un tiempo) al edén monolingüe. No estaría de más revisar la nula atención que dedican determinadas políticas nacionalistas (regionalistas o estatales) al asunto principal de

\footnotetext{
2 «¿Qué hemos de hacer nosotros, a principios del siglo XXI? Nuestras universidades y academias han abandonado casi todos los criterios estéticos e intelectuales, y se dedican a promocionar propagandistas de determinados intereses» (Bloom, 2002: 11-12).
} 
la enseñanza de las lenguas no propias. Remitámonos al contexto europeo; la Unión Europea post-Brexit tiene ante sí una paradójica circunstancia: la supresión (o no), en el catálogo de las veinticuatro lenguas actuales, de la oficialidad del inglés.

$$
- \text { y } 3-
$$

Mas no todo ha sido tragedia (ni comedia) traductológica: obvio es que la visibilidad de la traducción, como materia universitaria, como estudios oficiales y como actividad reconocida en el rango de la ciencia humanística, ha supuesto que los estudios lingüísticos ${ }^{3} \mathrm{y}$, sobre todo, los estudios literarios atiendan a las traducciones como parte de un legado cultural, lingüístico y literario que no puede considerarse, que nadie considera ya, ajeno; lo cual quiere (o debe) decir que la espuma de la teoría, su apogeo académico, por más catálogos, categorías, nomenclaturas y taxonomías que idee, no puede sustraerse de pareceres como el de Henri Meschonic:

El principal problema de la traducción, e incluso el único, es su teoría del lenguaje. Sin saberlo, cuando pensamos que estamos traduciendo un texto, lo que mostramos es la propia representación del lenguaje, que se interpone entre el texto que se traduce y la intención del traductor. Si nos situamos en lo discontinuo del signo lingǘstico para traducir un poema, no traducimos el poema, traducimos sólo de una lengua a otra lengua. Dicho de otro modo: no sabemos lo que hacemos. Y no sabemos que no sabemos lo que hacemos. De esto se desprende que la teoría del lenguaje depende de su teoría de la literatura, que toda traducción depende de su teoría del lenguaje, que toda teoría del lenguaje depende de su teoría del ritmo, que lo discontinuo depende de lo continuo, por lo que toda teoría del lenguaje depende de su teoría y práctica de la traducción, así como la traducción depende de su teoría del lenguaje (Meschonic, 2011: 1).

Por lo que concluye:

\footnotetext{
${ }^{3}$ En su brillantemente delirante o delirantemente brillante ensayo Le Schizo et les langues, Paris, Gallimard, 1970, pág. 13, Louis Wolfson sentencia: «La traduction, impliquant une décomposition phonétique du mot, et ne se faisant pas dans une langue déterminée, mais dans un magma qui réunit toutes les langues contre la langue maternelle, est une destruction délibérée, une annihilation concertée, un désossement, puisque les consonnes sont l'os du langage. La traduction se confond donc avec une linguistique générale ; mais l'étudiant peut assigner comme motif de toute linguistique générale le désir de tuer la langue maternelle».
} 
Debemos decir inmediatamente que no es sólo un problema epistemológico. Es también, inextricablemente, un problema cultural: un problema de historia del pensamiento del lenguaje. Por lo que sería ingenuo creer que hoy tenemos más conocimientos gracias a la lingüística formalista del siglo XX, a la historia de la hermenéutica y a la filosofía que, por ejemplo, en la antigüedad (Meschonic, 2012: 4).

Y aquí me permitiré recordar una escena cinematográfica que puede resultar una parábola de lo que vengo exponiendo. En la película The burt locker (2008), el sargento William James es uno de los miembros de un equipo de desactivación de explosivos en el Bagdad tomado por las tropas estadounidenses. El foco de la acción se centra en la descripción de la tarea, en el relato detallado de la desactivación y, secundariamente, en la resaca posterior a los picos de adrenalina sufridos o gozados. Antes de que tal vida se convierta en rutina, o precisamente porque de la rutina nace el error, el sargento William James es devuelto a su vida civil (esposa, hijo pequeño, barrio residencial, coche familiar); acompaña a su familia a un hipermercado y sus ojos y la cámara recorren morosamente un muro en forma de pasillo constituido, solamente, por cajas de cereales para el desayuno, de todos los colores, sabores y variedades imaginables. ¿Cómo traducir eso? ¿Cómo no entender en ese mundo de colores, música y luces blancas un orbe más peligroso, y más incomprensible, que la acción misma de desactivación o detonación de una bomba en las calles polvorientas y sin asfalto de Bagdad?

Volviendo al Kenyon College, lugar de la conferencia de Foster Wallace, fue allí, en su revista (The Kenyon Review) donde en 1982 el poeta Robert Bly firmó su famoso trabajo The Eight Stages of Translation, ensayo que debería ser de obligada lectura para todo aquel que se proponga, en algún momento, traducir textos literarios. A partir de uno de los Sonetos a Orfeo de Rilke, el poeta norteamericano desgrana sus ocho etapas y, en definitiva, viene a recordarnos cómo la traducción (literaria o no; en su caso, poética) es un acto de lectura. Y como acto de lectura que es, debe ser inagotable, revisable: debe ser, en definitiva, una relectura sucesiva. No de otro modo se alcanza una versión (un texto escrito en nuestra propia lengua) que nos resulte propio y a un tiempo ajeno: lectura, escritura, Filología.

La textura del mundo, dije ya hace más de tres lustros, es apariencia de realidad susceptible de ser texto (Ruiz Casanova, 2005: 7-45; reimp: Ruiz Casanova, 2020: 185-219). Comprender la textura del mundo implica, necesariamente, ser capaces de desentrañar su constitución sígnica y ser capaces de expresar verbalmente tanto el hallazgo, desde un punto de vista teórico, como alcanzar la realización verbal que da cuenta de ello. Tantas veces la ciencia humanística se ha volcado sobre los contenidos comunicables y tan pocas sobre las 
formas de expresar dichos contenidos, que al igual que damos por buenas las teorías aun cuando éstas no vengan arropadas por un estilo de escritura, en el ámbito de la traducción (también de la traducción literaria) estamos dando, asimismo, por buenas las fórmulas expresivas por encima de las formas de expresión. Y lo que estamos generando, quizá sin advertirlo o sin darle importancia, es un mundo en el que la transmisión, ese eje fundamental del acto educativo, ha sido (como dirían algunos aspirantes a neólogos) removida. Por acabar en el punto del que arrancaron estas palabras, recordaré aquí las últimas líneas del ensayo al que me refería:

El temor del teniente Drogo, en forma de metáfora en la novela de Buzzati y en la realidad, no es la llegada de los bárbaros sino la abolición de una idea (la Europa humanística) que será suplantada por una realidad bárbara: el autorreconocimiento y, en definitiva, la negación por ausencia de fuera, alli, entonces y ello o ellos. Sin tiempo, sin lugar, sin persona gramatical; así comienza a relatarse la nueva historia de la cultura, en la más absoluta ignorancia de todo lo que no está en uno mismo. Bienvenidos al Fin de la Intimidad, del cual ya estamos escribiendo, ahora mismo, su prólogo (Ruiz Casanova, 2020: 226).

De modo que sobre las ruinas de los presentes y de los futuros Estudios de Traducción, aquejados de indolencia por mor de la corrección política (y del oportunismo) de unos discursos sociales que nacen, crecen y se reproducen en el anonimato de eso que llaman redes sociales, sobre unos guetos lingüísticos, literarios, intelectuales y educativos que no nos hacen mejores lectores, ni mejores escritores ni, por lo tanto, mejores traductores, se alzará aquella famélica legión de lectores (y de escritores) que nos recordará, un día cualquiera, la leyenda final de Fabrenheit 451: ser libros.

Porque traducir no otra cosa es que la pretensión de ser libro, de ser texto. Jaime Gil de Biedma dixit: «Yo creía que quería ser poeta, pero en el fondo quería ser poema». 


\section{BIBLIOGRAFÍA}

Bloom, Harold (2002): El futuro de la imaginación, traducción al español de Daniel Najmías, Barcelona, Anagrama.

Bly, Robert (1982): «The Eight Stages of Translation», The Kenyon Univ. Review, 4, 2: 68-89.

Bonnefoy, Yves (2002): La Traducción de la Poesía, traducción al español de Arturo Carrera, Valencia, Pre-Textos.

Foster Wallace, David (2014): Esto es agua, traducción al español de Javier Calvo, Barcelona, Random House.

Grossman, Edith (2011): Por qué la traducción importa, traducción al español de Elvio E. Gandolfo, Buenos Aires, Katz Editores.

Meschonic, Henri (2011): «Traducir en el siglo XXI», traducción al español de Fátima Sainz, Boletin del Taller de Traducción Literaria de la Universidad de La Laguna, 2, 1.

Meschonic, Henri (2012): «Traducir en el siglo XXI», traducción al español de Fátima Sainz, Boletin del Taller de Traducción Literaria de la Universidad de La Laguna, 3, 4.

Polizzotti, Mark (2020): Simpatía por el traidor. Manifiesto por la traducción, trad. de Íñigo García Ureta, Madrid, Trama editorial.

Ruiz Casanova, José Francisco (2005): «La escritura del traductor», en José Francisco Ruiz Casanova, Henriette Partzsch y Florence Pennone, De Poesia y Traducción, Madrid, Biblioteca Nueva.

Ruiz Casanova, José Francisco (2020): Traducir la traducción, Madrid, Cátedra.

Steiner, George (2006): Los logócratas, traducción al español de María Cóndor, Madrid, Siruela.

Wolfson, Louis (1970): Le Schizo et les langues, Paris, Gallimard. 
SOBRE EL AUTOR

\section{José Francisco Ruiz Casanova}

Profesor Titular de Universidad.

Universidad Pompeu Fabra.

Contact information:

Departament de Traducció i Ciències del Llenguatge

TRILCAT: Grup de Recerca en Traducció, Recepció i Literatura

+34935421253

jose.ruiz@upf.edu

Roc Boronat, 13808018 Barcelona 